\title{
EDUCAÇÃO INCLUSIVA: UM PANORAMA SOBRE O DESENVOLVIMENTO E EFETIVAÇÃO DO ENSINO INCLUSIVO NO INTERIOR DO AMAZONAS
}

\author{
INCLUSIVE EDUCATION: PANORAMA ANALYSIS OF DEVELOPMENT AND \\ EFFECTIVENESS OF INCLUSIVE SCHOOLS IN AMAZON REGION
}

DOI: $10.23926 / R P D .2526-2149.2020 . v 5 . n 2 . p 1428-1448 . i d 803$

\section{Lucas Martins de Almeida \\ Graduado em Ciências: \\ Biologia e Química (UFAM) \\ Professor substituto na \\ Universidade Federal do \\ Amazonas (UFAM) \\ professorlucas.almeida@hot mail.com}

\section{Maria Aparecida Silva Furtado}

Doutora em Linguística

(UFMG)

Professora Adjunta na

Universidade Federal do

Amazonas (UFAM)

mariapfurtado@gmail.com

\section{Klenicy Kazumy de \\ Lima Yamaguchi}

Doutora em Química

(UFAM)

Professora Adjunta na

Universidade Federal do

Amazonas (UFAM)

klenicy@gmail.com
Resumo: Este trabalho visou investigar o perfil docente e o modo como professores atuantes na área de Ciências do Ensino Regular, dos níveis Fundamental e Médio, de escolas públicas da rede municipal e estadual do município de Coari, no interior do Amazonas, Brasil, percebem o ensino inclusivo e identificam as dificuldades inerentes à inclusão, bem como a situação de acessibilidade nessas escolas. Para tanto, foi formulado e aplicado, no período do segundo semestre letivo de 2019, um questionário para 23 professores. Adotou-se, como metodologia, uma abordagem quantitativa de caráter descritivo e exploratório. Os dados obtidos demonstraram que a formação docente acerca dessa temática é insuficiente, já que os docentes analisados se sentem inseguros para receber alunos com necessidades especiais. As contribuições oriundas dos resultados obtidos revelaram existir uma necessidade de refletir e de agir sobre educação inclusiva, tanto no aspecto de acesso físico e educacional de alunos, quanto no relacionado à formação dos professores. Espera-se que esse trabalho possa contribuir para uma reflexão acerca de maior sensibilização social para esse tema e que mais pesquisas sobre o ensino inclusivo e acessibilidade possam acontecer a fim de promover um ensino igualitário no sistema educacional.

Palavras-chave: Formação Acadêmica. Docência. Ensino Inclusivo. Amazonas.

\begin{abstract}
This research aims to analyze the perception of teachers working in the area of basic Education Sciences, from the primary and secondary levels of public schools in Coari city, Amazonas, Brazil, on inclusive education, and indicate difficulties inherent in this type of education and the situation of accessibility in schools. The questionnaire was formulated and applied for 23 teachers to identify the profile of the teachers studied and their perspectives on inclusive education. A descriptive and exploratory quantitative approach was adopted as a methodology. The data obtained showed that teacher training on this subject is insufficient, since the teachers analyzed feel insecure to receive students with special needs. The contributions derived from the results obtained reveal that it is necessary to reflect and act on inclusive education, both in terms of physical and educational access to students, and in relation to teacher training. It is hoped that this work can contribute to a reflection on greater social awareness on this topic and that more research on inclusive education and accessibility can be carried out to promote equitable education in the education system.
\end{abstract}

Keywords: Academic Training. Education. Inclusive Education. Amazonas. 


\section{INTRODUÇÃO}

A Constituição da República Federativa do Brasil de 1988 (CF/88), (BRASIL, 1988) assegura o direito de igualdade a todos os cidadãos sem nenhuma forma de restrição. Na mesma direção, leis e portarias municipais, estaduais e federais também preconizam o mesmo direito. Entretanto, em se tratando das temáticas acessibilidade e educação inclusiva, parece que o país ainda tem muito a avançar para que o direito à igualdade seja, de fato, garantido. Percebe-se, por exemplo, que possuir algum tipo de deficiência em um país marcado por grandes contrastes e desigualdades sociais como o Brasil, significa, conforme dizem os autores Pletsch (2009) e Almeida et al (2019), estar mais distante de receber uma educação de qualidade

A acessibilidade e a educação inclusiva são assuntos que permeiam debates na área de ensino. Segundo o Censo (IBGE, 2010), no Brasil, existem cerca de 24,5 milhões de pessoas com algum tipo de incapacidade ou deficiência, correspondendo a 14,5\% da população total. Diante desse cenário, verifica-se a existência de um discurso focado na valorização da diversidade humana e na compreensão da deficiência como componentes de discussão.

Alunos com Necessidades Educacionais Especiais (ANEE), mesmo diante de toda a evolução educacional, ainda enfrentam problemas que os restringem o acesso à inclusão em ambientes de formação do ensino, sendo perceptível as dificuldades que ainda sofrem para adquirirem a mesma inserção e qualidade oferecidas aos demais discentes (FERRARI; SEKKEL, 2007) e (GOMES et al, 2010). Por outro lado, também se verifica que nem sempre os docentes se encontram preparados ou capacitados para receberem, de forma inclusiva, os ANEE, sendo este um problema que precisa ser verificado. Conjectura-se que essa carência possa ser explicada devido à formação acadêmica, à "falta de identificação na área ou outras características pessoais", conforme será desenvolvido na seção 2.2, à frente (SILVA, 2011). Diante disso, procura-se responder às seguintes perguntas: qual é o perfil dos professores pesquisados? Como esses docentes percebem a educação inclusiva?

A educação inclusiva busca promover um olhar igualitário em meio à diversidade (CASTRO et al, 2018). Neste sentido, o papel ativo assumido pelos profissionais da educação, em especial, os docentes, é de suma importância nesse processo de inclusão a fim de minimizar a desigualdade no ensino. Ainda com o desenvolvimento de políticas educacionais de integração, verifica-se que são escassos os dados sobre a perspectiva docente em relação ao ensino inclusivo e as dificuldades que norteiam a sua efetivação no ambiente escolar.

Em face dessas considerações, o presente trabalho apresenta como objetivo investigar o perfil docente e o modo como professores atuantes na área de Ciências do Ensino Regular, dos 
níveis Fundamental e Médio, de escolas públicas da rede municipal e estadual do município de Coari, no interior do Amazonas, Brasil, percebem o ensino inclusivo e identificam as dificuldades inerentes à inclusão, bem como a situação de acessibilidade nessas escolas.

A seguir, são apresentados os pressupostos legais e teóricos de ensino e de inclusão e uma reflexão sobre a acessibilidade e a formação docente, constituindo-se partes integrantes da seção denominada referencial teórico. Na sequência, o quadro metodológico, especificando detalhamento do instrumento de coleta de dados, tipos de pesquisa e abordagem analítica. Já a seção quatro foi dedicada à análise, apresentação dos resultados e discussão. A seção cinco apresenta as considerações finais e, por fim, as referências utilizadas na construção deste trabalho.

\section{REFERENCIAL TEÓRICO}

\subsection{EDUCAÇÃO INCLUSIVA: PRESSUPOSTOS LEGAIS E TEÓRICOS DE ENSINO E INCLUSÃO}

Conforme anunciado na introdução, o direito de igualdade é assegurado a todos os brasileiros pela Constituição da República Federativa do Brasil de 1988 (CF/88), (BRASIL, 1988) e isso, como é de conhecimento geral, também se aplica à educação. Assim, a escolarização é direito de todos os brasileiros, inclusive daqueles que necessitam de uma educação especial, os quais se encontram inseridos no ensino regular, respaldados por leis que regulamentam o ensino na rede pública e privada (BRASIL, 2015). Apesar de ser defendido como um princípio e assinalado por discussões e até mesmo contradições, a busca de igualdade de oportunidades e de qualidade, na prática de muitas instituições de ensino, parece ser marcada por certa defasagem de ações que realmente promovam a inclusão escolar (CASTRO et al, 2018).

A educação especial tem como objetivo ampliar as possibilidades do educando com deficiência a se desenvolver e aprimorar-se na sua capacidade física e intelectual. Além disso, tende a oferecer, a este tipo de estudante, um ambiente social interativo, com estrutura física e mobiliária adaptada, carecendo de profissionais especializados para que, de fato, ocorra a inserção com equidade (CASTRO et al, 2018).

Conforme expressa Pereira et al (2019), até pouco tempo, o acolhimento de pessoas com deficiência no sistema educacional era realizado por meio de escola especial, sendo esses alunos separados nesta modalidade de ensino. Nos últimos anos, entretanto, esse cenário, em virtude de intensos debates, fóruns, reflexões e legislação, vem sendo alterado com novas práticas que 
inserem esses alunos no ensino regular. O debate que se faz necessário nesta nova fase é o de manter medidas cabíveis para efetivação de uma educação inclusiva sobre a qual se tenha o respeito e a garantia do direito do ensino inclusivo nas escolas com ensino regular.

É com a promulgação da Lei 9.394, no ano de 1996, a qual estabelece as Diretrizes e Bases da Educação Nacional no Brasil (BRASIL, 1996), que o acesso à educação de pessoas portadoras de necessidades especiais passa a ser disponibilizado a esse público alvo. No artigo $\mathrm{n}^{\circ} 58$ dessa Lei, a Educação Especial é definida como uma modalidade de educação escolar a ser ofertada, de preferência, na rede regular de ensino, a estudantes portadores de necessidades especiais. Desde então, novas estratégias de ensino vêm sendo elaboradas para a incorporação desses estudantes a fim de eliminar o comportamento discriminatório existente e ampliar a flexibilidade do sistema educativo.

Além da Lei de Diretrizes e Bases na Educação Brasileira (LDB 9394/96), também há de se destacar a Declaração de Salamanca e linha de Ação Sobre Necessidades Educativas Especiais, adotadas em Assembleia Geral, datada em 10 de junho de 1994 (BRASIL, 1994), que estabelece "Procedimentos-Padrões das Nações Unidas para a Equalização de Oportunidades para Pessoas com Deficiência”. Destacam-se, nesse documento, fatores relativos às adaptações das escolas inclusivas, incluindo políticas públicas e provisão financeira para alteração de prédios (espaço físico) e outras alterações como treinamento profissional, modificações de currículo, da organização escolar, da pedagogia e da avaliação. Apropriação de uma rede contínua de apoio à aprendizagem e à integração de crianças e jovens com necessidades educacionais especiais, dada por professores especializados para a ajuda mínima na classe regular. Neste sentido, além do papel do professor da classe regular e do professor de suporte especializado, o papel das famílias, dos administradores escolares e dos governos tornam-se imprescindíveis para uma educação especial bem-sucedida.

De acordo com as orientações oficiais dessa Declaração de Salamanca (BRASIL, 1994, p. 3), "as escolas deveriam acomodar todas as crianças independentemente de suas condições físicas, intelectuais, sociais, emocionais, linguísticas ou outras". Neste sentido, percebe-se avanço na legislação a fim de assegurar ao discente com necessidades especiais o direito de ser escolarizado em ambiente do ensino regular. A inserção desse aluno no ensino regular, entretanto, requer um planejamento especial, pois, conforme afirma Neves et al (2019), o ensino inclusivo provoca grandes mudanças nas escolas que necessitam de adaptação para garantir que a instituição não seja um local de segregação, mas, sim, de integração. 
A fim de adequar a realidade escolar ao que preconizam as orientações oficiais e a legitimidade dos atos educacionais, garantidos constitucionalmente, serviços especializados e articulações governamentais têm sido desenvolvidos visando a inclusão. Os desafios são enormes e, às vezes, surgem dos próprios profissionais que deveriam ser os agentes centrais da mudança in lócus. Desse modo, a educação especial sofre de empecilhos diversos e, neste caso específico, enfrenta manifestações de muitos profissionais os quais, de acordo com Filho e Kassar (2019), não estariam preparados para exercer esse modelo desafiador de educação.

Diante desses pressupostos legais e teóricos do ensino inclusivo e diante da grande diversidade sociocultural que o Brasil se dispõe, torna-se necessário que o professor compreenda as mudanças na educação a fim de atender as normativas de inclusão educacional. Conforme será desenvolvido na seção a seguir, a formação profissional precisa adequar-se às necessidades e aos desafios da inclusão para que o docente saiba executar, mobilizar e articular seus conhecimentos e suas competências mediante a uma ação reflexiva (PLESTSH, 2009).

\subsection{EDUCAÇÃO INCLUSIVA: DA ACESSIBILIDADE À FORMAÇÃO DOS PROFESSORES}

As escolas deveriam constituir-se como exemplos a serem seguidos pela sociedade no que diz respeito à inclusão social dos ANEE. Entretanto o que se percebe é que o direito à educação tem sido negado ou restringido para muitas pessoas, principalmente para aquelas que não possuem uma característica física ou intelectual, considerada "padrão" pela sociedade, como é o caso de portadores de alguma necessidade especial. Esse fato mostra-se mais claro ao serem avaliados, por exemplo, os critérios de inclusão, em que, comumente, verifica-se a falta de acessibilidade presente nas escolas, seja em termos arquitetônicos, urbanísticos, de transporte, de aspectos ligados à comunicação (sinalização) e, até mesmo, de acesso à informação (SMEHA; FERREIRA, 2008).

Os trabalhos na área de inclusão, relacionados à acessibilidade, assim como relatos de muitos docentes atuantes no ensino inclusivo, demonstram que a maioria dos estabelecimentos educacionais não estão preparados para acolherem pessoas com necessidades especiais. Os motivos relatados são diversos. Dentre eles, destacam-se falta de infraestrutura, barreiras econômicas, falta de planejamento na construção das escolas e ausência de preparação durante a formação docente. (MOREJÓN, 2009).

Percebe-se a necessidade de medidas governamentais, as quais devem contemplar direitos educacionais para os sujeitos portadores de necessidades especiais. Muitas ações já são realidade e estão sendo executadas, mas se comparadas aos desafios enormes que as escolas 
enfrentam para atenderem à demanda dessa população especial, tais medidas são insuficientes. Nota-se que muitas escolas não se encontram adaptadas e amparadas para prestar à sociedade um serviço de qualidade no que diz respeito, por exemplo, até mesmo à estrutura física dos prédios, quanto mais à qualificação de seus professores para lidarem com a inclusão.

Em se tratando especificamente da acessibilidade, verifica-se que o mínimo de estrutura, como o acesso a rampas ou vagas de estacionamento para pessoas com deficiência deve ser levado em consideração. A Lei 13.146, de 6 de julho de 2015, garante aos deficientes o direito à educação, considerando os diferentes níveis educacionais e o aprendizado. Nesse sentido, os estabelecimentos educacionais devem se adequar para dar garantia aos sujeitos às condições de acesso, permanência e participação (BRASIL, 2015). Devem seguir normas vigentes, tais como a NBR 9050, da Associação Brasileira de Normas Técnicas (ABNT, 2004), que estabelece as principais normas para as pessoas com necessidades especiais no Brasil, o Decreto Federal 5.296/2004, que regulamenta a Lei 10.048/2000, da prioridade de atendimentos, e a Lei 10.098/2000, da promoção de acessibilidade às pessoas com deficiência ou mobilidade reduzida (BRASIL, 2004).

Uma análise desse contexto educacional deve ser feita, entretanto, para além de um exame do espaço físico da escola. Requer uma reflexão sobre os processos de formação dos educadores que atuam no interior das escolas. Conforme já dito, a inclusão não se resume a uma infraestrutura adaptada, mas requer, também, sensibilidade docente sobre as demandas e limitações dos alunos com necessidades especiais. O professor precisa estar preparado para enfrentar os desafios impostos pela prática educativa escolar da atualidade e que, acima de tudo, se relacionem com a pluralidade da sala de aula (FERNANDES; REIS, 2018).

A capacitação do profissional docente se inicia com a formação inicial na graduação, mas deve também ser um processo contínuo de formação, já que o meio onde o professor atua se modifica rotineiramente para atender sempre a novos alunos que chegam às escolas. Assim, a formação deve se adequar sempre aos ambientes vivenciados in lócus. A formação, conforme diz Cruz \& Glalt (2014), é um fenômeno que deve ocorrer durante todo o exercício da docência e que precisa estar integrado às práticas sociais existentes e desafiadoras.

Assumir compromisso com uma formação contínua para a tarefa educativa em toda a sua complexidade é primordial ao docente, principalmente devido à existência de demandas ou tematizações que não são abordadas com tanta clareza ou, muitas vezes, nem são vistas na graduação, ou seja, na formação inicial do professor. 
Sem uma formação inicial ou continuada eficiente, muitos professores não têm sabido lidar com uma intervenção inclusiva notória e eficaz comprometida com o ensino e a aprendizagem. (ULIANA; LEITE, 2018).

O tema inclusão é abordado nos cursos de licenciaturas devido a sua complexidade desafiadora, mas, dada à necessidade de adequação à realidade escolar, a sua abordagem ainda parece incipiente. Nos cursos de ciências, que envolvem aprendizado de Biologia e Química, como é o caso abordado nesta pesquisa, ou de Física e Ciências da Natureza, percebe-se que tais conteúdos são vistos como de difícil compreensão e, quando se trata da educação inclusiva, essa dificuldade torna-se ainda mais potencializada devido às limitações que o aluno com necessidades especiais possui. Diante disso, a temática inclusão deve estar presente na formação inicial, mas também na formação continuada para capacitar o profissional docente a um exercício diário de ensino planejado, com metodologias adequadas para o ensino inclusivo (CONSTANTINO; DORNELES, 2019). Com base nisso, esta pesquisa apresenta o olhar ou a percepção de professores de Ciências sobre a inclusão no ensino regular das escolas. A seguir, são apresentados os procedimentos metodológicos deste estudo realizado.

\section{Metodologia}

Este estudo foi desenvolvido por meio de pesquisa bibliográfica e de pesquisa de campo (MARCONI. LAKATOS, 2020) e (SEVERINO, 2016). A pesquisa de campo, de acordo com Severino (2016, p.131 ) consiste em coletar os dados " nas condições naturais em que os fenômenos ocorrem". Já a pesquisa bibliográfica "é aquela que se realiza a partir do registro disponível, decorrente de pesquisas anteriores" (SEVERINO, 2016, p.131 ). Assim, foi feito levantamento bibliográfico sobre o tema, obtido de livros impressos e artigos científicos disponíveis na rede mundial de computadores. A pesquisa de campo, por sua vez, foi realizada em escolas públicas da rede municipal e estadual do município de Coari, localizado a aproximadamente $363 \mathrm{Km}$ de Manaus, capital do estado, situado na Região do Médio Solimões, Amazonas, Brasil,

Nessa pesquisa de campo foram selecionados como sujeitos de pesquisa 23 professores. Como critérios de seleção, foram adotados a inclusão de docentes atuantes na área de Ciências do Ensino regular, dos níveis Fundamental e Médio e a condição do aceite em fazer parte desta pesquisa por meio do preenchimento de um questionário e do Termo de Consentimento Livre e Esclarecido (TCLE). A coleta de dados se deu por meio do instrumento ‘questionário' que foi aplicado no período do segundo semestre letivo de 2019 e que continha questões abertas e 
fechadas. As questões abertas permitiram aos participantes uma maior liberdade de expressão e ajudaram os pesquisadores a compreenderem melhor a percepção desses sujeitos sobre a temática abordada. Já as questões fechadas permitiram a este estudo a quantificação da percepção dos docentes analisados. Todos os sujeitos tiveram seu anonimato garantido por meio da não identificação do questionário. Esta pesquisa foi aprovada pelo comitê de ética e apresenta o Certificado de Apresentação para Apreciação Ética (CAAE) no 20000719.2.0000.5020.

Para análise dos dados coletados, adotou-se uma metodologia de análise com abordagem quantitativa de caráter descritivo e exploratório. De acordo com Severino (2016), a abordagem quantitativa possui característica original do método científico de configuração experimental-matemática. Assim, com esta abordagem, foi possível quantificar e descrever os sentidos e as significações dadas ao conjunto de percepções, sentimentos e vivências da população estudada.

O questionário aplicado aos professores foi dividido em quatro partes. Na primeira parte foi realizada a identificação dos professores com as seguintes variáveis: idade; sexo; formação acadêmica; pós-graduação; tempo de atuação profissional; participação em eventos de educação inclusiva; escola na qual trabalhavam; nível de escolaridade em que ministravam aula e a disciplina sobre a qual exerciam sua docência.

$\mathrm{Na}$ segunda parte, o foco da pesquisa foi saber a compreensão dos professores sobre a educação inclusiva, dando destaque para a conceituação, as ideias e as opiniões que tais profissionais têm acerca da educação inclusiva. Neste sentido, foi solicitado aos professores: 1) conceituar educação inclusiva; 2) indicar a presença em participações em eventos como minicursos, palestras e disciplinas sobre a temática; 3) informar se suas formações acadêmicas foram adequadas para eles lidarem com ensino inclusivo; 4) informar se possuíam alunos com necessidades especiais; e 5) indicar os tipos de deficiência encontradas na sua sala de aula.

$\mathrm{Na}$ terceira parte foi solicitado aos participantes da pesquisa que expressassem sobre o desenvolvimento do processo de inclusão, apresentando as dificuldades por eles encontradas na realização das aulas, tais como: 1) indicar as principais dificuldades na elaboração das aulas para a inclusão de alunos com necessidades especiais; 2) revelar se estavam preparados para realizarem a educação inclusiva e o que faltava para que isso fosse realizado.

Por fim, na quarta parte foi solicitado aos docentes que apresentassem sugestões para viabilização da inclusão escolar, apresentando a(s) condição(ções) necessária(as) à efetivação da educação inclusiva, tais como: 1) indicando se a escola possuía estrutura adequada para 
receber alunos com necessidades especiais; 2) indicando se existia na escola material didático específico de ensino-aprendizagem para alunos com necessidades especiais e profissional especialista para o atendimento a tais alunos; 3) indicando como classificariam a escola onde atuavam em termos de qualidade concernente à inclusão escolar; 4) indicando a sua avaliação quanto à sua preparação para a atuação na educação inclusiva e revelando se pretendiam realizar alguma qualificação em relação à temática.

A análise dos dados ocorreu a partir da tabulação dos resultados. Os dados obtidos foram submetidos à análise estatística utilizando o programa de estatística R 2.14.0® para Windows, sendo estes apresentados sob a forma de percentual e de número absoluto. Também foi desenvolvido sobre o material coletado uma análise descritiva da perspectiva docente sobre a inclusão a fim de realizar o objetivo geral desta pesquisa. Os resultados decorrentes da investigação feita foram apresentados de maneira sintética e à luz das principais variáveis selecionadas.

\section{Resultados e Discussão}

É importante ressaltar que a escolha do tema deste trabalho surgiu a partir do desejo dos pesquisadores de conhecerem a realidade da vivência docente com o ensino inclusivo. Verificase que, embora exista preocupação com os direitos igualitários aplicados a estudantes com necessidades especiais, nem sempre a concretização desses direitos recebe a atenção desejável a esta demanda, tanto por parte de governos quanto por parte da sociedade.

Conforme já expresso, buscou-se analisar a percepção de professores da área das Ciências sobre o ensino inclusivo. Espera-se que o resultado possa contribuir com a pesquisa nessa área temática.

O total de professores que responderam ao questionário foram 23 , sendo destes, $57 \%$ $(n=13)$ do sexo feminino e $43 \%(n=10)$ do sexo masculino. A formação acadêmica desses sujeitos foi identificada em relação a quatro cursos diferentes, sendo assim distribuída: $39 \%$ $(\mathrm{n}=9)$ possuem formação em Licenciatura em Ciências: Biologia e Química; 35\% (n=8) em Ciências Natural; 18\% ( $n=4)$ em Ciências Biológica; 4\% ( $n=1)$ em Ciências: Matemática e Física e 4\% (n=1) em Normal Superior. O resultado das áreas de formação dos docentes pode ser observado na Figura 1. 
Figura 1 - Formação dos professores analisados

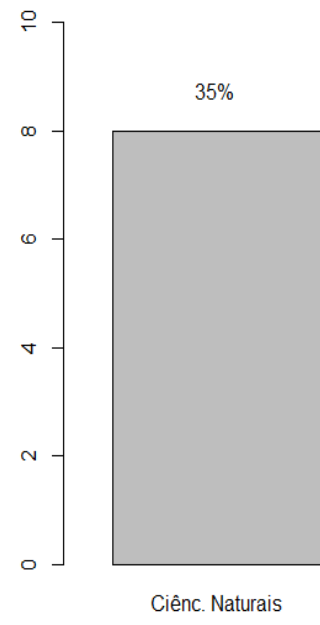

Ciênc. Naturais

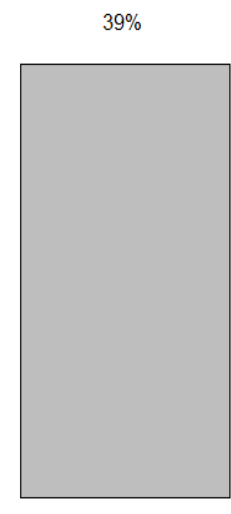

Ciênc.: Biologia e Química

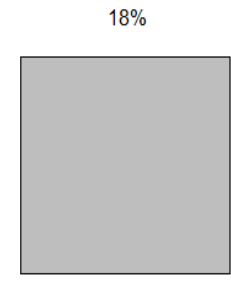

Ciências Biológicas Formação

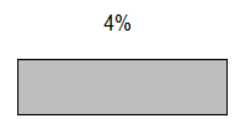

Ciênc.: Matemática e Fisica

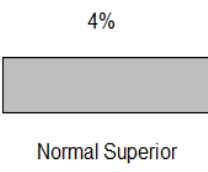

Fonte: Os próprios autores. Dados primários (2020).

A grande parte dos professores declarou possuir formação em Licenciatura em Ciências: Biologia e Química. Esse resultado pode ser explicado devido ao fato de este curso ser oferecido no próprio município pela Universidade Federal do Amazonas e por ter grande procura da população local.

Quanto à atuação dos professores dentro da área das Ciências, segundo as modalidades de ensino, foram encontrados os seguintes resultados: 43,5\% $(n=10)$ dos professores pesquisados declararam ministrar aulas no Ensino Médio; 43,5\% $(n=10)$ no Fundamental com a disciplina Ciências e 13\% $(n=3)$ exerciam a docência tanto no Ensino Médio quanto no Ensino Fundamental. Em se tratando da atuação dos professores no Ensino Médio, 67\% (n=8) relataram que lecionavam a disciplina Química e 33\% (n=4) ministravam Biologia.

Também foi identificado a capacitação dos 23 professores em nível de formação continuada e constatou-se que há um percentual considerável de docentes que possuem algum tipo de pós-graduação: $65 \%(n=15)$. Dentro desses quinze professores, destacam-se dois que declararam possuir mestrado, sendo um na área de Química e outro na área de Biologia, fato que qualifica o ensino no município. A presença da Universidade Federal do Amazonas no município de Coari/AM tem contribuído para a graduação ou formação inicial dos professores todos anos na área de ensino de Ciências e tem aquecido o mercado de trabalho. Muitos desses professores buscam uma qualificação enquanto formação continuada para estarem mais aptos ao trabalho de docência. Entretanto, apesar dessa busca, dos sujeitos analisados, nenhum possui especialização relacionada à temática de ensino inclusivo, conforme o resultado demonstrado na Tabela 1, abaixo. 
Tabela 1 - Capacitação dos professores investigados

\begin{tabular}{c|c}
\hline Pós-Graduação & Quantidade (\%) \\
\hline Ciência animal tropical (mestrado) & 6,67 \\
\hline $\begin{array}{c}\text { Metodologia do Ensino Superior } \\
\text { Mestrado em Química }\end{array}$ & 6,67 \\
\hline Organização e Gestão Escolar & 6,67 \\
\hline Gestão Ambiental & 6,67 \\
\hline Educação de Jovens e Adultos - EJA & 6,67 \\
\hline Metodologia em Matemática e Física & 6,67 \\
\hline Metodologia para o Ensino de Bio/Quí & 26,63 \\
\hline Educação Infantil & 6,7 \\
\hline Ludopedagogia & 6,67 \\
\hline Educação para o Desenvolvimento Sustentável & 6,67 \\
\hline Ciências & 6,67 \\
\hline Supervisão Escolar & 6,67 \\
\hline
\end{tabular}

Fonte: Os próprios autores. Dados primários (2020).

Um dos maiores desafios para as universidades e instituições de ensino que oferecem qualificação profissional é formar educadores que não sejam apenas reprodutores de conhecimentos, mas que sejam docentes aptos a enfrentarem a diversidade social inserida em uma sala de aula. No que se refere à educação inclusiva, os professores devem estar capacitados para construírem nas diferentes formas de ensino e adaptarem atividades e conteúdo para alunos com necessidades educacionais especiais e, assim, desenvolver o conhecimento científico de forma igualitária.

Nesse caso, as universidades e instituições de qualificação profissional devem trabalhar com a formação continuada de professores para que, de fato, ocorra o mínimo necessário para uma educação inclusiva (SANT’ANA, 2005).

Dadas as demandas constantes da ANNE, torna-se fundamental a capacitação continuada dos professores para atuarem com a educação inclusiva, mas é na formação inicial que o despertar os docentes deve acontecer para a problemática social existente, a fim de preparar o futuro professor para os muitos problemas que podem surgir na profissão (ALMEIDA et al, 2019).

Num olhar panorâmico sobre a realidade das escolas Brasil afora, percebe-se que os docentes não estão preparados para atuarem em realidades inclusivas, tendo em vista, que uma formação de qualidade não está ligada a apenas uma capacitação pessoal no âmbito teórico sobre ensino inclusivo e/ou legislativo. Essa capacitação está inserida a uma nova visão do saber ensinar com alicerces ligados a uma aprendizagem baseada em atitudes que favoreçam o processo de ensino inclusivo (SANCHES; TEODORO, 2007).

Nesta pesquisa, embora os docentes não tenham apresentado especialização na área de inclusão, verificou-se que há certo conhecimento sobre a temática: a maioria dos professores 
analisados, cerca de $61 \%(n=14)$ souberam conceituar educação inclusiva. Do universo dos 23 professores, 30\% $(\mathrm{n}=7)$ conceituaram parcialmente e apenas $9 \%(\mathrm{n}=2)$ não souberam conceituar. Esse resultado é reflexo da formação inicial dos professores e tem explicação no fato de que, durante a formação universitária, há, por parte dos futuros professores, a participação em palestras e em minicursos sobre educação inclusiva. Na formação universitária docente, há de se destacar, por exemplo, o papel importante da disciplina de Língua Brasileira de Sinais (LIBRAS), que aborda a sua aplicação na educação, o contexto histórico e a legislação que assegura os direitos dessa comunidade especial. Tais experiências, de certa forma, resultam nos primeiros contatos dos docentes com Educação Especial. Nesta pesquisa, $61 \%(n=14)$ dos docentes afirmaram que tiveram contato com ensino inclusivo já na graduação, $13 \%(\mathrm{n}=3)$ afirmaram que tiveram parcialmente e $(26 \% ; n=6)$ não tiveram contato.

Também foi analisado o tempo de atuação dos docentes. Com relação a isso, obteve-se uma média de 16,7 anos de função dos professores entrevistados, conforme demonstrado na figura 2. Esse tempo de trabalho dos docentes pode provocar o levantamento de algumas variáveis positivas e negativas. Se, por um lado, o vasto tempo de serviço gera uma adaptação ao ensino, somado a uma vasta experiência relacionada aos desafios do universo escolar, tais como as mudanças sociais e o aumento de alunos com necessidades especiais, por outro, esse tempo de serviço também pode ocasionar um comodismo e desmotivação frente às problemáticas escolares.

Figura 2 - Tempo de atuação profissional dos docentes

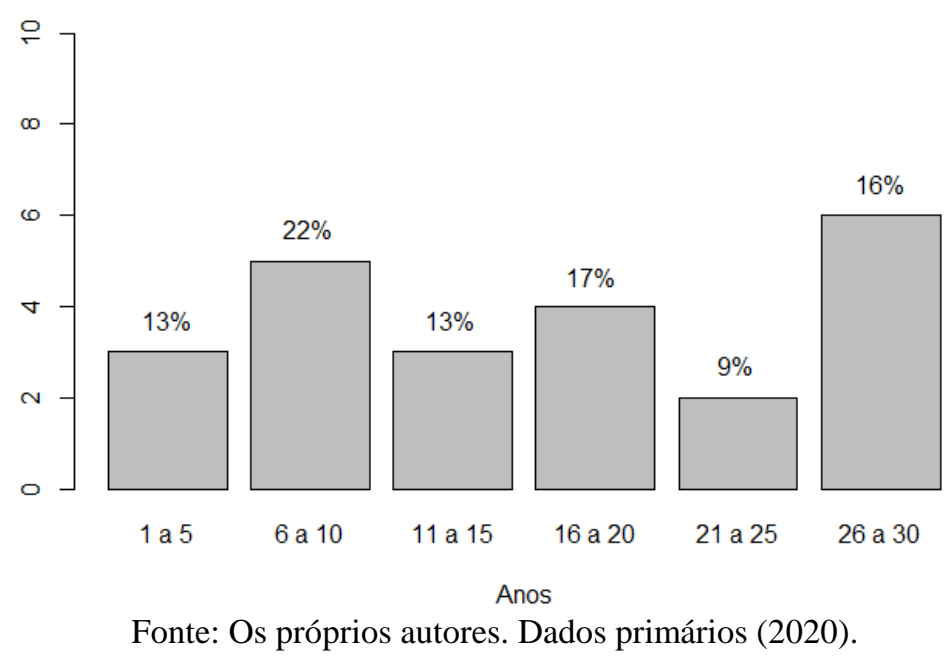

As pesquisas no âmbito educacional em relação à inclusão abrangem investigações relacionadas ao tempo de serviço e ao preparo docente. Segundo Sampaio e Morgado (2014), os professores que têm menos tempo de serviço são mais favoráveis a metodologias de inclusão 
em relação aos que têm mais tempo de serviço. No entanto, os dados coletados a partir do questionário deste estudo ora apresentado demonstra que $87 \%$ dos professores que têm acima de 10 anos de tempo de serviço pretendem realizar uma qualificação relacionada ao ensino inclusivo, demonstrando a motivação desses profissionais em se capacitarem.

\subsection{DiFiCULDADES NA FORMAÇão PARA O EXERCíCIO DO ENSINO INCLUSIVO}

Os dados obtidos e apresentados a seguir na Figura 3 dizem respeito à "conceituação da educação inclusiva", à "participação de eventos sobre a temática" e "ao relato se a graduação foi adequada para os professores lidarem com ensino inclusivo". Os resultados confirmam a problemática das dificuldades na formação para o exercício do ensino inclusivo. Ao se fazer uma comparação entre essas três variáveis citadas, verificou-se que, $61 \%$ dos docentes afirmaram que sabiam conceitos sobre educação inclusiva, tendo $30 \%$ dos que não sabiam conceituar e $9 \%$ dos que conheciam parcialmente. Em se tratando da informação sobre a participação em eventos, a maior parte revelou que já participou de eventos com a temática (61\% sim, 30\% não e 9\% parcialmente). Quanto ao fato de se sentir preparado, um número considerável de docentes, cerca de $74 \%$, revelaram não se sentir preparados pela formação acadêmica para atuarem com os ANEE, tendo apenas $26 \%$ deles que revelaram estar parcialmente preparados.

Das atividades descritas sobre educação especial, os professores citaram: Estágio em instituição (7\%), palestras e minicursos (36\%), cursos de LIBRAS (14\%), formação continuada na área $(7 \%)$ e disciplina de LIBRAS no curso de graduação (36\%).

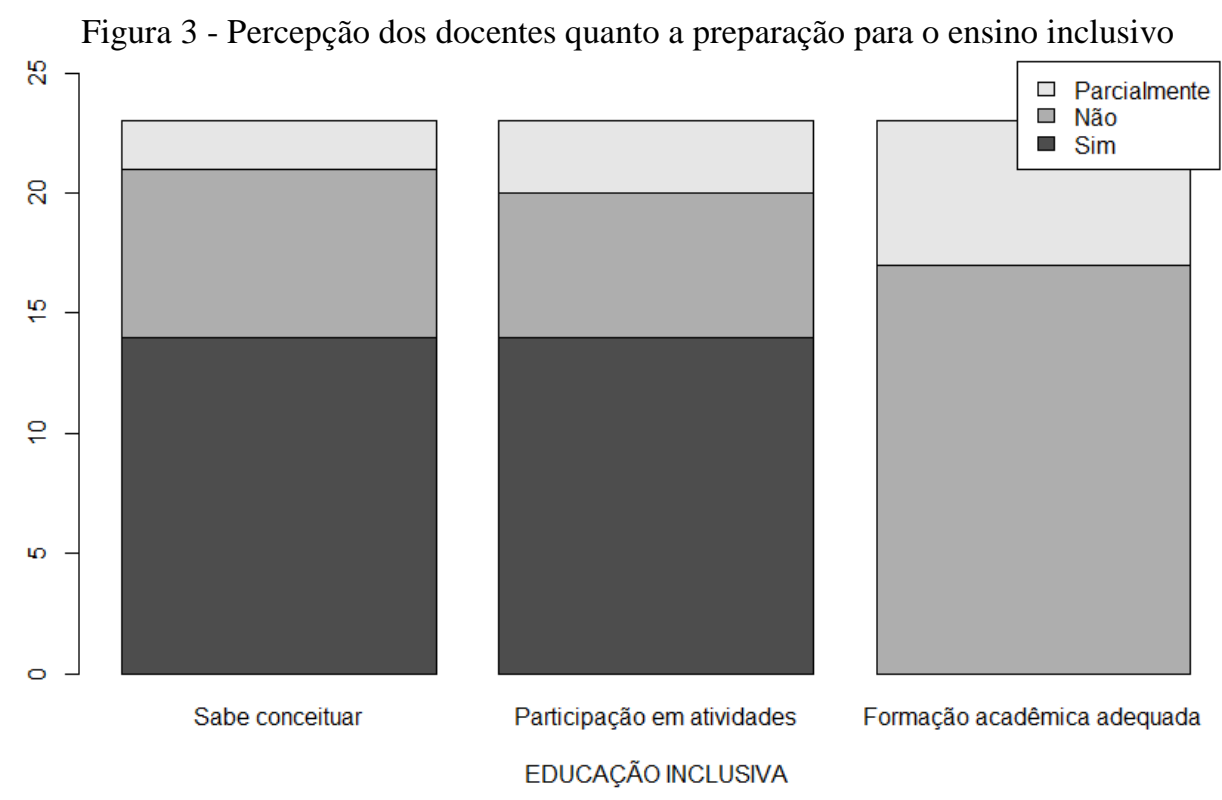

Fonte: Os próprios autores. Dados primários (2020). 
Como já expresso anteriormente, a qualificação dos professores para atuarem no ensino inclusivo é preconizada na Declaração de Salamanca (BRASIL, 1994) e pela Lei de Diretrizes e Base da Educação (BRASIL, 1994) que direciona o ensino especial à escola de ensino regular e visa a integração de todos sem diferenciação entre os seres. Segundo Cruz \& Glat (2014), nos cursos de Licenciaturas são comuns as críticas da falta de uma consistência na atenção da educação especial. Assim, se a formação universitária não foi adequada, faz-se necessário as capacitações, visando atualizações sobre a temática tanto por parte dos docentes, quanto por parte do corpo pedagógico de uma escola.

A busca de efetivação dos processos de ensino e de aprendizagem com alunos de necessidades especiais conjectura uma trajetória histórica de desafios árduos que não podem ser desprezados e implica em responsabilidades ainda que em partes, em processos formativos (graduação) que na prática desempenharão a função de propor diferentes ferramentas de ensino na educação básica (MONTEIRO; MANZINI, 2008)

A primazia da universidade é o ensino. Nesse contexto, a formação de professores, é, sem dúvida, um dos aspectos determinantes para a efetivação de uma política de inclusão educacional já que um dos grandes empecilhos para a inclusão é a carência na formação dos docentes. Nesse aspecto, as instituições formadoras têm a responsabilidade de promover uma preparação adequada e que condiz com a realidade (CARDOSO; HORA, 2019).

A formação docente no curso de Licenciatura em Ciências: Biologia e Química, ofertado no Instituto de Saúde e Biotecnologia da Universidade Federal do Amazonas (ISB/UFAM), apresenta ao graduando um contato inicial com o ensino inclusivo, neste caso, direcionado ao ensino de estudantes surdos. Essa formação se dá por meio da disciplina de Língua Brasileira de Sinais (LIBRAS), presente na grade curricular do curso. Além dessa experiência, outro contato citado pelos sujeitos pesquisados na sua formação é a participação em minicursos e palestras.

Como se vê, ainda é incipiente a formação de professores para atuarem com inclusão. A efetivação do ensino inclusivo não deve restringir-se apenas à disciplina de LIBRAS, levando em consideração a diversidade de restrições que os ANEE apresentam. A busca pela qualificação deve implicar em processos constantes, oferecendo condições de ensino diferentes para cada um discente, a fim de refletir a prática pedagógica nos processos de construção do conhecimento científico igualitário (SANT'ANA, 2005). 


\subsection{CONDIÇÕES PARA EFETIVAÇÃO DA EDUCAÇÃo INCLUSIVA}

Os resultados apresentados nesta seção revelam os condicionantes para a efetivação do ensino inclusivo. Quando perguntado aos professores se eles já haviam tido experiência com alunos com necessidades especiais, 43\% $(n=10)$ afirmaram que já tiveram ou tinham no momento desta pesquisa e $57 \%(n=13)$ não tiveram em nenhum momento. Acerca das questões 'informar se possuíam alunos com necessidades especiais e indicar os tipos de deficiência encontradas na sua sala de aula, os professores que relataram a presença de ANEE destacaram os seguintes tipos: Autismo (20\%), Deficiente Auditivo (52\%), Síndrome de Down (7\%), Cadeirante (7\%), Deficiente Visual (7\%) e Dislexia (7\%).

Como se vê, a presença de ANEE é uma realidade na sala de aula e é também um desafio a ser enfrentado por todos os professores. Esta pesquisa apresenta uma realidade comumente encontrada na prática da docência.

A maior parte dos ANEE relatados apresenta deficiência auditiva $(n=8)$ e a inclusão desses alunos em sistema educacional regular deve atribuir mudanças e adaptações nos currículos dos professores para, de fato, promover a integração social e cultural desses discentes. A presença do aluno com deficiência auditiva em sala faz com que o professor tenha a necessidade de articular novas estratégias de ensino e se adeque ao aluno surdo (GONÇALVES; FESTA, 2013).

Também foi questionado quais seriam as maiores dificuldades dos professores na elaboração de aulas para incluir os alunos com necessidades especiais. Na perspectiva dos docentes, 35\% ( $\mathrm{n}=8)$ alegaram falta de qualificação para facilitar a elaboração das aulas inclusivas, $13 \%(n=3)$ descreveram a falta de comunicação (como no caso de ANEE surdos), $22 \%(n=5)$ relataram a ausência de recursos didáticos, 13\% $(n=3)$ citaram a ausência de um profissional que os auxilie na elaboração das aulas, $13 \%(n=3)$ citaram a adequação de conteúdos didáticos e $4 \%(n=1)$ não responderam.

A estrutura das escolas é também parte do processo de inclusão e estas precisam estar adaptadas para receberem alunos com essas necessidades. Com relação às adequações necessárias, 39\% ( $n=9)$ disseram que a escola não é adaptada para receber os alunos com deficiência, 35\% $(n=8)$ afirmam ser parcialmente e apenas $26 \%(n=6)$ consideram a escola adaptada para receberem os ANEE.

A acessibilidade nas escolas vai além de uma forma de inclusão, é acima de tudo o direito constitucional e, para que seja exercido o ensino inclusivo, as escolas têm a necessidade de se adequar frente às impossibilidades de cada indivíduo para que eles permaneçam na 
instituição e busquem o seu maior desenvolvimento possível. Para isso, a escola necessita de material didático, profissionais especializados, mobiliário e espaço físico adaptados (CASTRO et al, 2018).

As dificuldades apresentadas quanto à acessibilidade nas escolas dificultam a promoção do ensino. Quando perguntado como o professor classificaria a escola concernente à inclusão educacional, analisando a estrutura física, profissionais específicos e sala de recursos, $52 \%$ $(n=12)$ expressaram regular, ou seja, a maioria analisa certa distância daquilo que seria o ideal para o ensino inclusivo, $26 \%(\mathrm{n}=6)$ disseram ser bom, $9 \%(\mathrm{n}=2)$ acreditavam ser ótimo e precário respectivamente e $4 \%(n=3)$ afirmaram ser ruim.

Nessa mesma perspectiva e corroborando com os resultados expressos anteriormente, $69 \%(\mathrm{n}=19)$ dos docentes afirmaram que não se sentiam totalmente preparados para realizarem aulas inclusivas com os ANEE. Ao avaliarem o posicionamento sobre o ensino inclusivo, nenhum deles revelou se sentir preparado com a temática. Neste quesito, a pesquisa obteve os seguintes resultados: 4\% $(\mathrm{n}=1)$ não optaram; 39\% $(\mathrm{n}=9)$ reconheceram não estar preparados e $57 \%(\mathrm{n}=13)$ não se sentiam preparados. Por outro lado, todos os professores expressaram desejo de buscar uma qualificação quando thes perguntado se ainda pretendiam realizar alguma capacitação em relação à inclusão, conforme se constata nestes resultados: $91 \%(\mathrm{n}=21)$ deles pretendiam realizar uma capacitação e $9 \%(n=2)$ não pretendiam realizar qualquer curso ou participar de algum evento relacionado à temática.

Com relação ao que faltava para os professores na realização do ensino inclusivo, 50\% deles $(\mathrm{n}=9)$ citaram uma formação continuada para estarem aptos à realidade educacional; 17\% $(\mathrm{n}=3)$ disseram preparação pessoal; $11 \%(\mathrm{n}=2)$ expressaram uma qualificação na área específica; $11 \%(\mathrm{n}=2)$ afirmaram ausência do domínio em LIBRAS e 5\% (n=1) disseram uma reciclagem.

Como se vê, todas as respostas dos professores clamam a necessidade de uma capacitação para lidarem com a questão. Neste sentido, a formação continuada vem como caminho mais promissor para promover um conhecimento mais sólido para o professor, no exercício da sua profissão, saber conduzir o ensino inclusivo, permitindo a tais alunos possibilidades mais seguras e consistentes no processo de ensino e aprendizagem (CARDOSO; HORA, 2019).

Fernandes e Reis (2018) abordam aspectos sobre a formação continuada de professores e apontam a necessidade e a importância de um aprimoramento contínuo para promoção do ensino inclusivo, ainda que exista dificuldade e resistência docente na participação. Dessa 
forma, o professor deve ser um facilitador para o aluno, inserindo-o no seu contexto para melhor compreensão (SMEHA; FERREIRA, 2008). É necessário que exista uma comunicação por meio de uma linguagem facilitadora, propondo ferramentas essenciais ao aprendizado significativo (LINHARES et al, 2014).

A inclusão escolar é uma temática que tem ganhado bastante espaço no meio educacional e vem quebrando paradigmas em relação ao ensino. Esse tema vem mostrando as necessidades que as escolas têm de assistir o alunado com necessidades educacionais especiais e mostra as diferenças intrínsecas à condição humana (BRESSAN et al, 2019).

A causa mais importante para o ensino inclusivo é o valor social da equidade. Dito de outra forma, é respeitar que em sala de aula há diversidade étnica, religiosa e social, é entender que o professor leciona através do exemplo e que, apesar das diferenças, todos estão no mesmo patamar em termos de direitos (CONSTANTINO; DORNELES, 2019).

O sistema educacional brasileiro é dinâmico e a busca por uma qualificação que atenda aos discentes com necessidades especiais de forma eficiente é de extrema relevância. $O$ cenário mundial está em constante mudança e a recepção da diversidade dos ANEE faz parte da competência docente (FERNANDES; REIS, 2018). Durante muitos anos, no ensino tradicional, as especificidades individuais não foram contempladas, mas atualmente isso não pode continuar mais acontecendo e a falha de cursos de formação inicial ou a falta da formação continuada não podem ser uma pretexto que justifique a estagnação profissional no fazer diferente em sala de aula.

O número de discentes diagnosticados por meio de déficits de aprendizagem, deficiência auditiva, transtorno de autismo, dentre outros, é uma realidade cada vez mais presente na sala de aula e demanda por um acompanhamento mais cuidadoso é fundamental. Se a base acadêmica apresenta carência na formação inicial que aproxime o professor de tal realidade, então é o momento de investir na formação continuada e de refletir sobre a questão pelo viés do papel social que esses profissionais apresentam, tanto como orientadores de um processo construtivo de conhecimento, quanto na contribuição para uma humanidade em que a diversidade seja contemplada no ensino para que, de fato, seja chamado de ensino inclusivo.

As dimensões em que os aspectos da inclusão possuem não se esgotam aqui e motivam pesquisas futuras a fim de preencherem as lacunas abertas e existentes relacionadas ao ensino inclusivo, em especial ao modo de implementar propostas inclusivas. Sabe-se que o caminho é longo, porém com o esforço, dedicação e a contribuição de todos visando o mesmo objetivo, a inclusão será cada vez mais uma realidade e não uma utopia. 


\section{CONSIDERAÇÕES FINAIS}

Este trabalho investigou o perfil docente e o modo como os professores pesquisados percebem o ensino inclusivo, identificam as dificuldades inerentes à inclusão e veem a situação de acessibilidade nas escolas. Os dados analisados responderam às questões levantadas, apresentado o perfil dos sujeitos e suas percepções acerca da temática em estudo. Verificou-se que os professores apresentaram um perfil de qualificação profissional com especialização e mestrado, mas não na área de ensino inclusivo. Por outro lado, eles revelaram que buscam aperfeiçoar-se por meio de minicursos e palestras. Isso, porém, não parece suficiente já que, na percepção dos professores, eles não se sentiam totalmente preparados para atuarem com discentes com necessidades especiais. Esses dados confirmam a conjectura inicial de que essa carência possa ser explicada devido a precariedade da formação docente e a falta de identificação desses profissionais nesta área de atuação. A formação continuada nessa temática mostrou-se ser um caminho e está entre os anseios desses profissionais.

Por fim, no que diz respeito à situação de acessibilidade nas escolas, a percepção dos docentes revelou que há dificuldades para a efetivação da inclusão, como, por exemplo, a infraestrutura escolar que é um entrave para o ensino integrador.

As contribuições oriundas das análises e dos resultados obtidos neste estudo revelaram a necessidade de haver mais reflexão e ação sobre a educação inclusiva, tanto do ponto de vista do acesso físico e educacional de alunos, quanto do relacionado à formação dos professores, como um processo contínuo de mudanças. A qualificação permanente de docentes envolvidos no processo educacional é fundamental, mas ela não resolve tudo. A educação inclusiva é um desafio e uma tarefa que deve ser abraçada por todos cidadãos, seja professores, gestores, administradores de política pública educacional ou outros diretamente envolvidos na temática.

A inclusão deve reforçar a ideia de igualdade em uma sociedade que busca o desenvolvimento social e intelectual, mantendo sempre o direito a todos e promovendo a aceitação do próximo. Os processos de inclusão não devem apenas adequar-se aos espaços para acessibilidade e a presença de profissionais especializados. Deve ser um desafio permanente, não permitindo acomodações. Dessa forma, é preciso movimentar-se em busca de mudanças e estratégias de ensino que busque considerar a heterogeneidade como um valor e sem discriminação. 


\section{REFERÊNCIAS}

ALMEIDA, Elzenir Pereira de Oliveira; OLIVEIRA, José Lucas Santos; ALVES, Cynthia Arielly Alves; SANTOS, Thayana Maria Medeiros; SILVA, Edevaldo. Percepção de professores sobre a educação inclusiva em uma instituição de nível superior no semiárido paraibano. Scientia Plena. v. 15, n. 1, p.1-8, 2019. DOI: 10.14808/sci.plena.2019.019902.

ASSOCIAÇÃO BRASILEIRA DE NORMAS TÉCNICAS (ABNT). NBR 9050:

Acessibilidade aedificações, mobiliário, espaços e equipamentos urbanos. 2004. Rio de Janeiro, 2004.

BRASIL. Lei no 9.394, de 20 de dezembro de 1996. Disponível em:

http://www.planalto.gov.br/ccivil_03/leis/19394.htm. Acesso em 16 jan. 2020.

BRASIL. Decreto n ${ }^{0}$ 5.296. Brasília, DF, 2 de dezembro de 2004. Disponível em: https://www.udesc.br/arquivos/udesc/documentos/Decreto_n_5_296_2004_15226898494688 7091.pdf. Acesso em 16 jan. 2020.

BRASIL. Lei no 13.146, de 6 de julho de 2015. Disponível em: http://www.planalto.gov.br/ccivil_03/_ato2015-2018/2015/lei/113146.htm. Acesso em 16 jan. 2020.

BRASIL. Constituição (1988). Constituição da República Federativa do Brasil. Brasília, DF. 1988. Disponível em:

https://www2.senado.leg.br/bdsf/bitstream/handle/id/518231/CF88_Livro_EC91_2016.pdf. Acesso em 16 jan. 2020.

BRASIL. Declaração de Salamanca e Linha de Ação Sobre Necessidades Educativas Especiais. Brasília: UNESCO, 1994. Disponível em: http://portal.mec.gov.br/seesp/arquivos/pdf/salamanca.pdf. Acesso em 4 fev. 2020.

BRESSAN, Luiza Liene; BUSS, Beatriz Schueroff; LEWCOWICZ, Alexandra Aline. inclusão em foco: um estudo de caso sobre um deficiente que possui surdo cegueira no ensino regular. Revista Educação Especial, Santa Maria, v. 32, p. ,2019. DOI: $10.5902 / 1984686 \times 24891$

CARDOSO, Maisa Oliveira; HORA, Genigleide Santos. Formação continuada de professores: mediação da aprendizagem matemática. Estudos IATT, Salvador, v.4, n.1, p. 152$168,2019$.

CASTRO, Gisélia Gonçalves; ABRAHÃO, César Augusto França; NUNES, Ângelo Xavier; NASCIMENTO, Lilian Cristina Gomes; FIGUEREDO, Glória Lúcia Alves. Inclusão de alunos com deficiências em escolas da rede estadual: um estudo sobre acessibilidade e adaptações estruturais. Revista Educação Especial, Santa Maria| v. 31, n. 60, p. 93-106, 2018.

CONSTANTINO, Ana Luiza Alves; DORNELES, Aline Machado. Educar para alteridade na formação de professores de química: experiências vividas com a educação de surdos. Revista Latino-Americana de Estudos em Cultura e Sociedade, Rio Grande do Sul, v. 5, ed. especial, p.1-17, 2019. 
CRUZ, Gilmar de Carvalho; GLAT, Rosana. Educação inclusiva: desafio, descuido e responsabilidade de cursos de licenciatura. Educar em Revista, Paraná, v.1, n. 52, p. 257 273, 2014.

FERNANDES, Jomara Mendes; REIS, Ivone de Freitas. O papel da formação continuada no trabalho dos professores de Química com alunos Surdos. Revista Educação Especial, v. 32, p.1-16, 2018. DOI: 10.5902/1984686X

FERRARI, Marian. AL Dias; SEKKEL, Marie Clarie, educação inclusiva no Ensino Superior: Um novo desafio. Psicologia Ciência e Profissão, v.27, n.4, p.636-647, 2007.

FILHO, Daniel. Mendes Silva; KASSAR, Mônica Carvalho Magalhães. Acessibilidade nas escolas como uma questão de direitos humanos. Revista Educação Especial, Santa Maria, v. 32, 2019. DOI: $10.5902 / 1984686$ X29387

GOMES, Adriana Leite Lima Verde; POULIN, Jean-Robert; FIGUEREDO, Rita Vieira Educação Especial na Perspectiva da Inclusão Escolar: O Atendimento Educacional Especializado para Alunos com Deficiência Intelectual. Brasília - Ministério da Educação, Secretaria de Educação Especial, Fortaleza, Universidade Federal do Ceará, 2010.

GONÇALVES, Humberto Bueno; FESTA, Priscila Soares Vidal. Metodologia do professor no ensino de alunos surdos. Ensaio Pedagógicos, v.1, p.1-13, 2013.

IBGE. Censo demográfico. https://www.ibge.gov.br/estatisticas/sociais/populacao/9662censo-demografico-2010.html?edicao=9749\&t=destaques. Acesso em 29/6/2020.

LINHARES, Paulo Cássio Alves; IRINEU, Toni Halan da Silva; SILVA, Josimar Nogueira; FIGUEREDO, Janailson Pereira; SOUSA, Thiago Pereira. A importância da escola, aluno, estágio supervisionado e todo o processo educacional na formação inicial do professor.

Revista Terceiro incluído, v. 4, n. 2, p. 115-127, 2014.

MARCONI, Maria de Andrade; LAKATOS, Eva Maria; Metodologia do Trabalho Científico. $8^{\text {a }}$ ed. São Paulo, SP: Atlas, 2020.

MONTEIRO, Ana Paula Húngaro; MANZINI, Eduardo José. Mudanças nas concepções do professor do ensino fundamental em relação à inclusão após a entrada de alunos com deficiência em sua classe. Revista Brasileira de Educação, Marília, v.14, n.1, p.35-52, 2008.

MOREJÓN, Kizzy. O acesso e a acessibilidade de pessoas com deficiência no ensino superior público no estado do Rio Grande do Sul. 2009. 252 f. Tese (Doutorado em Ciências Área: Psicologia) - Universidade de São Paulo - USP, Ribeirão Preto - SP, 2009.

NEVES, Libéria Rodrigues; RAHME, Mônica Maria Farid and FERREIRA, Carla Mercês da Rocha Jatobá. Política de educação especial e os desafios de uma perspectiva inclusiva. Educação \& Realidade, Porto Alegre, v. 44, n. 1, p.84-85, 2019.

PEREIRA, Airton Reis; PEREIRA, Mírian Rosa; APINAGÉS, Marinalda Gomes. Memória e educação inclusiva: a prática de um grupo de professores de ciências naturais que trabalham com alunos deficientes, cidade de Marabá (PA). Brazilian Applied Science Review, Curitiba, v.3, n. 2, p. 1304-1314, 2019. 
PLETSCH, Márcia Denise. A formação de professores para a educação inclusiva: legislação, diretrizes políticas e resultados de pesquisas. Educar, v. 33, p. 143-156, 2009.

SAMPAIO, Catarina; MORGADO, José. As atitudes dos professores do primeiro ciclo do ensino básico face à educação inclusiva de alunos com necessidades educativas especiais.

Revista Interações, v.33, p. 163-188, 2014.

SANCHES, Isabel; TEODORO, António. Procurando indicadores de educação inclusiva: as práticas dos professores de apoio educativo. Revista Portuguesa de Educação, v. 20, n.2, p. 105-149, 2007.

SANT'ANA, Izabella Mendes. educação inclusiva: concepções de professores e diretores. Psicologia em Estudo, Maringá, v. 10, n. 2, p. 227-234, 2005.

SEVERINO, Antônio Joaquim. Metodologia do Trabalho Científico. 24. Ed, São Paulo: Cortez, 2016

SILVA, Ceris Salete Ribas da; CAFIERO, Delaine. Implicações das políticas educacionais no contexto do ensino fundamental de nove anos. Educação em Revista, v. 27, n. 2, p. 219-248, 2011 .

SMEHA, Luciane Najar; FERREIRA, Iolete de Vlieger. Prazer e sofrimento docente nos processos de inclusão escolar. Revista Educação Especial, Santa Maria, v.1, n. 31, p. 37-48, 2008 .

ULIANA, Márcia Rosa; LEITE, Eliana Alves Pereira. educação inclusiva no curso de extensão universitária: estratégias, recursos e materiais didáticos no ensino de matemática para estudantes da educação básica com deficiência visual. Pesquisa e Prática em educação inclusiva, Manaus, v. 1, n. 2, p.297-311, 2018.

Recebido em: 30 de junho de 2020.

Aprovado em: 31 de agosto de 2020. 